\title{
Torsional, flexural and torsional-flexural buckling of angle section members - an analytical approach
}

\author{
A. Beyer \& A. Bureau \\ CTICM, Saint-Aubin, France \\ J-P. Jaspart \& J.F. Demonceau \\ Liège University, Liège, Belgium \\ M-Z. Bezas \\ Liège University, Liège, Belgium \\ NTUA, Athens, Greece
}

\begin{abstract}
In the framework of the ongoing revision of EN 1993-3-1, the RCFS funded research project ANGELHY is currently performing experimental, numerical and theoretical studies on angle sections and lattice towers. This paper presents a particular aspect of the ANGELHY project and focusses on a theoretical study concerning the behaviour of angle section members. First, the elastic second order equation of such members subjected to axial compression is established. Then, this differential equation is solved based on different assumptions concerning geometric imperfections to determine second order displacements, rotations and internal forces and moments. The analytical second order solution is validated through comparisons to a numerical elastic second order analysis. Based on the validated analytical solution, it is then shown, that even if torsional/torsional-flexural buckling of angle section members was relevant according to the elastic critical loads, the member rather fails by flexural buckling only. The reason for this unexpected conclusion may be directly derived from the second order internal forces and moments as shown in the last part of this paper.
\end{abstract}

\section{INTRODUCTION}

Owing to the need to optimise steel lattice towers, the research on angle section members has been very active in the last fifteen years. Interesting contributions on different questions are provided for example in references (Vayas et al. 2009), (Spiliopoulos et al. 2017), (Moze et al. 2014) and (Kettler \& Unterweger 2017). Nonetheless, there exists still a lack concerning the theoretical background on member buckling and more specifically concerning the torsionalflexural buckling mode. In fact, generally, it is considered that angle section members subjected to a compression force may fail due to instability by flexural buckling about their weak axis $v$ (see Figure 1) or by torsional-flexural buckling combining displacements and torsional twist. Usually, the sensitivity to one or the other failure mode is evaluated based on the critical axial forces $N_{\mathrm{cr}, \mathrm{v}}$ (minor axis flexural buckling) and $N_{\mathrm{cr}, \mathrm{TF}}$ (torsional-flexural buckling). The expressions for $N_{\mathrm{cr}, \mathrm{v}}$ and $N_{\mathrm{cr}, \mathrm{TF}}$ are given in Equations (1) and (2).

$$
N_{c r, v}=E I_{v}\left(\frac{\pi}{L}\right)^{2}
$$




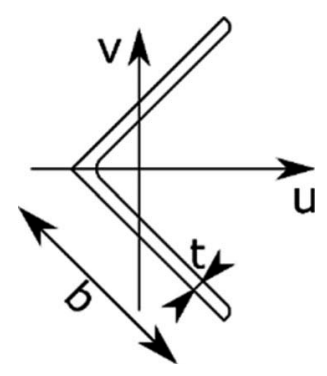

Figure 1. Definition of axes.

$$
N_{c r, T F}=\frac{i_{p}^{2}}{2\left(i_{p}^{2}-y_{s}^{2}\right)}\left(N_{c r, T}+N_{c r, u}-\sqrt{\left(N_{c r, T}-N_{c r, u}\right)^{2}+4 N_{c r, T} * N_{c r, u} \frac{y_{s}^{2}}{i_{p}^{2}}}\right)
$$

With:

$$
N_{c r, T}=\frac{1}{i_{p}^{2}} G I_{T}
$$

where: $E=$ Young's modulus; $I_{\mathrm{v}}=$ second moment of area about the minor axis; $L=$ member length; $i_{\mathrm{p}}=$ polar radius of inertia; $y_{\mathrm{s}}=$ distance between the shear centre and the centroid; $G=$ shear modulus, $I_{\mathrm{T}}=$ torsion constant.

Figure 1 shows the definition of axes. It should be noted that an axial compression force is considered as positive. Also, the major axis bending moment $M_{\mathrm{u}}$ is considered positive if it leads to compression of fibres with positive coordinate $\mathrm{v}$ and the minor axis bending moment $M_{\mathrm{v}}$ is considered positive if it leads to compression of fibres with positive coordinate $\mathrm{u}$.

In order to evaluate in which range torsional-flexural buckling may potentially be more critical than minor axis flexural buckling, it is interesting to compare the differences between $N_{\text {cr,TF }}$ and $N_{\text {cr,v }}$ for a given example. Figure 2 shows a comparison of the critical axial forces depending on the minor axis relative slenderness of a 150.150 .10 angle section member made of steel S355. This comparison suggests that torsional-flexural buckling may be a relevant failure mode up to a relative minor axis buckling slenderness of $1.0(L=2250 \mathrm{~mm})$. In particular, for legs of lattice towers, this value of the slenderness is in the practical range. Consequently, it is of importance to fill the lack of background on the torsional-flexural buckling of angle sections. Therefore, the following paragraphs will highlight, on a theoretical basis and analytical second order analyses, the behaviour of angle section members under compression.

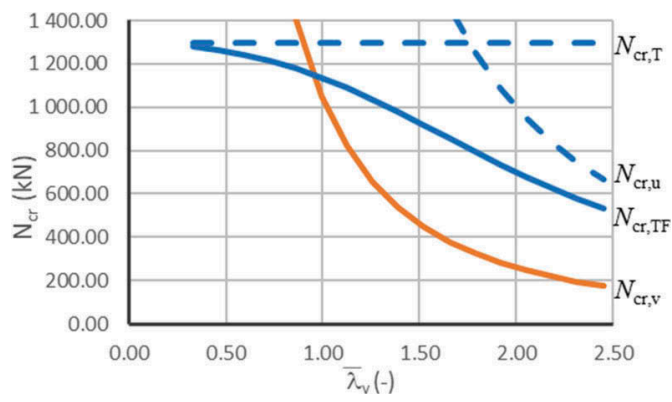

Figure 2. Critical axial forces for a given minor axis relative slenderness. 


\section{SECOND ORDER INTERNAL FORCES AND MOMENTS}

\subsection{Flexural buckling about the minor axis - Second order internal forces and moments}

First, it is recalled that the second order displacement $v$ and the second order bending moment $M_{\mathrm{v}}$ may be determined with equations (4) and (5). Both equations indicate that the second order quantities depend on the applied axial force $N$ and the amplitude of the chose imperfection $v_{0}$. In the framework of this study, an imperfection affine to a half sine wave has been chosen.

$$
\begin{gathered}
v=\frac{N v_{0}}{N_{c r, v}-N} \\
M_{v}=E l_{v} v^{I I}=-\frac{N v_{0}}{1-\frac{N}{N_{c r, v}}}
\end{gathered}
$$

Based on a realistic assumption of the amplitude of the equivalent imperfection $v_{0}$ (derived from physical tests and numerical simulations), the second order bending moment can be calculated and finally it is possible to apply a first yield criterion in order to obtain the member resistance:

$$
\sigma_{\max }=\frac{N}{A}+\frac{N v_{0}}{\left(1-\frac{N}{N_{c r, v}}\right) W_{e l, v}} \leq f_{y}
$$

where: $\sigma_{\max }=$ maximum stress in the cross-section; $W_{\mathrm{el}, \mathrm{v}}=$ elastic section modulus; $f_{\mathrm{y}}=$ yield stress.

Equation (6) can be used to derive the European buckling curves as has been done by (Rondal et al. 1979). This derivation is omitted here.

\subsection{Torsional-flexural buckling}

In this section, the second order internal forces and moments are derived for the case of torsional-flexural buckling. For this buckling mode, major axis flexural buckling is coupled with the torsional buckling. Consequently, the two coupled differential equations (7) and (8) have to be used to determine the second order quantities.

$$
\begin{aligned}
& E I_{u} w^{I I}-N y_{s} \varphi \varphi+N w w=-N w_{0}+N y_{s} \varphi_{0} \\
& -G I_{t} \varphi^{I}+N i_{p}^{2} \varphi^{I}-N y_{s} w^{I}=N y_{s} w_{0}^{I}-N i_{p}^{2} \varphi_{0}^{I}
\end{aligned}
$$

where: $\varphi=$ torsional twist, $w_{0}=$ the displacement component of the imperfection, $\varphi_{0}=$ the torsional twist component of the imperfection.

At this point, it should be highlighted that the equivalent imperfection is composed of two components here: $\varphi_{0}$ and $w_{0}$. It may be possible to choose values for both components independently. Nonetheless, if the imperfection is chosen affine to the eigen mode, a fixed ratio exists between the values of $w_{0}$ and $\varphi_{0}$ :

$$
w_{0}=\frac{y_{s}}{1-\frac{N_{c r, u}}{N_{c r, T F}}} \varphi_{0}=r_{w} \varphi_{0}
$$

Based on Equation (9), one may express the second order displacement components $w$ and $\varphi$ by: 


$$
\begin{gathered}
\varphi=-\frac{y_{s}^{2}\left(1-\frac{N_{c r, u}}{N} \frac{r_{w}}{y_{s}}\right)-i_{p}^{2}\left(1-\frac{N_{c r, u}}{N}\right)}{y_{s}^{2}-i_{p}^{2}\left(1-\frac{N_{c r, t}}{N}-\frac{N_{c r, u}}{N}+\frac{N_{c r, t N c r, y}}{N^{2}}\right)} \frac{w_{0}}{r_{w}} \\
w=\frac{N\left(\frac{y_{s}}{r_{w}}-1\right) w_{0}+N y_{s} \varphi}{N-N_{c r, u}}
\end{gathered}
$$

The second order internal forces and moments result from Equations (12) and (13):

$$
\begin{gathered}
M_{u}=E I_{u} w^{I I}=-\frac{N\left(\frac{y_{s}}{r_{w}}-1\right) w_{0}+N y_{s} \varphi}{1-\frac{N}{N_{c r, u}}} \\
M_{x}=M_{x, S t . V}=G I_{t} \varphi^{I}=\frac{\pi}{L} G I_{t} \frac{i_{p}^{2}\left(1-\frac{N_{c r, y}}{N}\right)-y_{s}^{2}\left(1-\frac{N_{c r, y}}{N} \frac{r_{w}}{y_{s}}\right)}{y_{s}^{2}-i_{p}^{2}\left(\frac{N_{c r, t}}{N}+\frac{N_{c r, y}}{N}-\frac{N_{c r, t N_{c r, y}}}{N^{2}}\right)} \frac{w_{0}}{r_{w}}
\end{gathered}
$$

It is important to note that the maximum second order major axis bending moment is located at mid span. Inversely, the Saint Venant's torsional moment is distributed according to a cosine half wave. Consequently, its maximum value, given in Equation (13), is located at the supports. Additionally, it should be recalled that the Saint Venant's torsional moment only generates shear stresses over the cross-section. Therefore, it is not possible to use a simple linear stress interaction as in Equation (6). Rather the maximum von Mises stress $\sigma_{v \text { Mises }}$ resulting from a combination of $N, M_{\mathrm{u}}$ and $M_{\mathrm{x}, \mathrm{St} . \mathrm{V}}$ should be checked along the member. The elastic resistance criterion consequently reads:

$$
\sigma_{v \text { Mises }}=\sqrt{\sigma_{x}^{2}\left(N, M_{u}\right)+3 \tau^{2}\left(M_{x, S t . V}\right)} \leq f_{y}
$$

where: $\sigma_{x}\left(N, M_{u}\right)=$ axial stress due to axial force and major axis bending; $\tau(M x,, S t . V)=$ shear stress due to Saint Venant's torsional moment.

In principle, it would be possible to derive a buckling curve for torsional-flexural buckling. However, even if this is not done here, it is clear from Equation (14) that this buckling curve cannot have the same format as the flexural buckling curves derived by (Rondal \& Maquoi 1979).

In the following section, the resistance criteria of Equations (6) and (14) will be applied to selected examples and compared to numerical simulations.

\section{COMPARISON TO NUMERICAL SIMULATIONS}

First, the second order results obtained in the previous paragraph will be validated by comparing the analytical solutions to elastic second order calculations. These elastic second order calculations are performed with the free software FE-STAB (Kindmann et al. 2013). This software allows the user to perform elastic $1^{\text {st }}$ and $2^{\text {nd }}$ order analyses including a geometric imperfection.

The second order results are compared based on an equivalent imperfection equal to L/250 corresponding to buckling curve $b$ according to EN 1993-1-1 (CEN 2005). The following calculations are performed for an angle section L150.150.10 and values of the relative slenderness $\lambda_{v}$ in the range of 0.5 to 1.25 . Table 1 presents the results. It should be noted that the geometric imperfection has been determined so that, for the torsional-flexural buckling mode, the combination of $w_{0}$ and $\varphi_{0}$ leads to a geometric imperfection of L/250 for one tip of the legs. 
Table 1. Second order displacements for the torsional-flexural buckling mode.

\begin{tabular}{|c|c|c|c|c|c|c|c|c|}
\hline \multirow{2}{*}{$\begin{array}{l}\text { Member } \\
\text { length } L\end{array}$} & \multirow[b]{3}{*}{$\lambda_{\mathrm{v}}$} & \multirow[b]{3}{*}{$N_{\mathrm{cr}, \mathrm{TF}} / N$} & \multicolumn{2}{|c|}{ Geometric imperfection } & \multicolumn{2}{|c|}{ Analytical solutions } & \multicolumn{2}{|c|}{ Numerical solutions } \\
\hline & & & $w_{0}$ & $\varphi_{0}$ & $w^{\mathrm{II}}$ & $\varphi^{\mathrm{II}}$ & $w^{\mathrm{II}}$ & $\varphi^{\mathrm{II}}$ \\
\hline$(\mathrm{mm})$ & & & $(\mathrm{mm})$ & $(\mathrm{rad})$ & $(\mathrm{mm})$ & (rad) & $(\mathrm{mm})$ & (rad) \\
\hline 570 & 0.25 & 3 & $1.55 \times 10^{-3}$ & $1.52 \times 10^{-3}$ & $\approx 0$ & 0.00076 & $\approx 0$ & 0.00076 \\
\hline 1150 & 0.50 & 3 & 0.0133 & 0.0306 & 0.0066 & 0.0153 & 0.0066 & 0.01531 \\
\hline 1700 & 0.75 & 3 & 0.0451 & 0.0451 & 0.0225 & 0.0225 & 0.0225 & 0.0225 \\
\hline 2250 & 1.00 & 3 & 0.1120 & 0.0591 & 0.0560 & 0.0295 & 0.0560 & 0.0295 \\
\hline $2850^{*}$ & 1.25 & 3 & 0.2460 & 0.0730 & 0.1230 & 0.0365 & 0.1230 & 0.0365 \\
\hline
\end{tabular}

* For $L=2850 \mathrm{~mm}: N_{\mathrm{cr}, \mathrm{u}}<N_{\mathrm{cr}, \mathrm{TF}}$

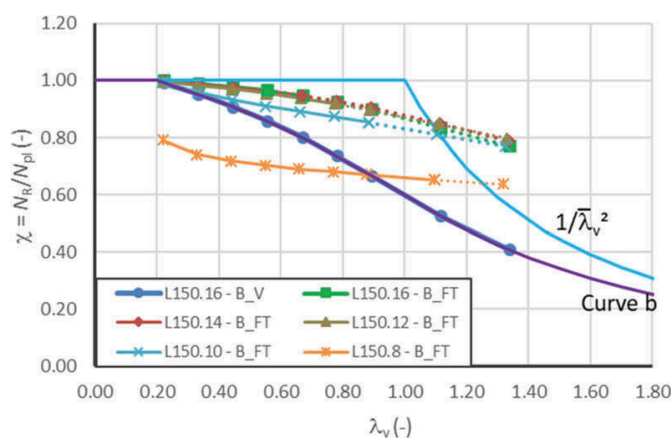

Figure 3. Analytical reduction curves for flexural and torsional-flexural buckling.

Table 1 provides the results for different member lengths. In order to obtain a significant second order amplification, the results are determined for a ratio $N_{\mathrm{cr}, \mathrm{TF}} / N$ equal to 3.0. Table 1 clearly indicates that the analytical solutions fit perfectly the numerically calculated displacement and torsional rotation.

Next, Figure 3 shows the obtained results for equal leg angle sections 150.16, 150.14, $150.12,150.10$ and 150.8 (b.t). The last angle section does not exist in classical cross-section catalogues but it is included here in order to enlarge the parameter field in terms of ratio $b / t$. It should be noted that the amplitude of the geometric imperfection applied in the analytical approach has been back calculated from buckling curve $b$, applicable for the buckling design of angle section members according to EN 1993-1-1 (CEN 2005). It is also recalled that the amplitude applied for the torsional-flexural buckling mode refers to the pre-deformation of the tip of one leg.

As the imperfection amplitude has been back calculated from the buckling curve, the analytically determined solution for minor axis flexural buckling (noted L150.16- B-V) perfectly overlaps European buckling curve $b$. As the minor axis buckling solutions are identical for all cross-sections, only the result for section L150.16 is represented. The analytical reduction curves determined for torsional-flexural buckling (based on Equation (14)), are divided into two parts:

- the continuous line indicates the slenderness range for which torsional-flexural buckling is relevant according to the critical axial forces $\left(N_{\mathrm{cr}, \mathrm{TF}}<N_{\mathrm{cr}, \mathrm{v}}\right)$;

- the dotted part of the curve indicates that minor axis flexural buckling is relevant $\left(N_{\mathrm{cr}, \mathrm{v}}<\right.$ $N_{\text {cr,TF. }}$ 
a)

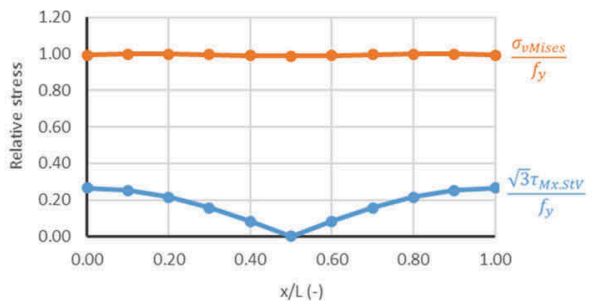

b)

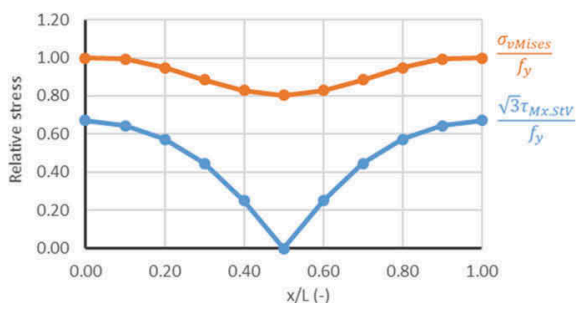

Figure 4. Evolution of shear stresses and von Mises stresses: a) section L150.10 with $L=750 \mathrm{~mm}$; b) section L150.8 with $L=750 \mathrm{~mm}$.

One may observe that, according to the analytical approach, only for section L150.8, the torsional-flexural buckling mode leads to a lower resistance than the minor axis flexural buckling mode. In fact, for the shortest members, the most loaded cross-section in case of torsional-flexural buckling is not the section at mid-span, but the section at the member ends. This section is subject to an interaction between shear stresses, resulting from Saint Venant's torsion, and axial stresses, resulting from the axial force. The major axis bending moment obviously vanishes at the member ends. When the member becomes longer, the section relevant for design in case of torsional-flexural buckling shifts from the member ends to midspan. For the longest members, the interaction between the axial force and the major axis bending moment becomes therefore relevant. Yet for these member lengths, minor axis flexural buckling is always much more critical. Observing Figure 3 again, one may remark the huge difference between section L150.8 and all other studied angle sections. The important strength reduction for this cross-section results from its low torsional constant $I_{\mathrm{t}}$. Two effects explain this observation: 1) the critical axial force for torsional-flexural buckling reduces highly and 2) the (elastic) resistance to Saint Venant's torsion also reduces highly. In order to represent this explanation, Figures 4 shows the evolution of the shear stresses and the von Mises stresses over the length of two members:

- Section L150.10 with a relative slenderness of $0.34(L=750 \mathrm{~mm})$;

- Section L150.8 with a relative slenderness of $0.34(L=750 \mathrm{~mm})$.

The stresses are represented as ratios with respect to the yield stress $f_{\mathrm{y}}$.

For section L150.10, Figure 4 a) shows that the shear stresses only represent approximatively $22 \%$ of the von Mises stresses. The main contribution to the von Mises stresses is resulting from the axial force. One may note that the maximum stress resulting from the second order major axis bending moment is only equal to $10 \mathrm{MPa}$ at mid-span.

In contrast, the shear stresses resulting from the Saint Venant's torsional moment highly contribute to the von Mises stresses in case of section L150.8. Owing to the high value of these shear stresses, the resistance, in terms of maximum axial force, of the section L150.8 with a length of $750 \mathrm{~mm}$ is much less than for section L150.10 with the same length.

\section{CONCLUSIONS}

This paper has presented an analytical approach to assess the torsional-flexural buckling behaviour of angle section members. It has been recalled that, based on the critical axial force, torsional-flexural buckling may be a relevant failure mode in the practical slenderness range of such members. However, the analytical derivation of a design criterion, conducted through rigorous second order theory has highlighted that the Eurocode 3 Part 1-1 design approach for torsional-flexural buckling is not suited for this failure mode. In fact, the Eurocode 3 buckling reduction curves have been determined based on the assumption that only axial stresses 
interact and lead to failure at mid height of a column. Yet, as angle sections possess only a negligible warping stiffness the second order torsional twist, developing in case of torsionalflexural buckling, does not lead to axial stresses but to shear stresses resulting from the Saint Venant's torsional moment. The maximum second order elastic stresses consequently result from an interaction between shear stresses and axial stresses near the member ends. This interaction appears to be much more favourable than the interaction between axial force and second order bending in case of flexural buckling. The Eurocode 3 provisions should therefore be amended. Nonetheless, it is recalled that the presented results possess certain limitations as they have been obtained following elastic second order theory based on certain assumptions. In particular:

- The amplitude of the equivalent geometric imperfection has been chosen equal for flexural buckling and torsional-flexural buckling.

- The resistance criterion for torsional-flexural buckling used here is purely elastic. A more refined plastic interaction could potentially lead to even higher resistance for torsionalflexural buckling.

- The effect of local buckling is not accounted for.

Finally, it is recalled that this research is part of the RFCS project ANGELHY. In the framework of this project, the mentioned limitations of this analytical approach are currently eliminated owing to an extensive laboratory testing campaign and numerical studies considering imperfections and material non linearity (GMNIA).

The present work has been realised in the framework of the research project ANGLEHY partially funded by the Research Fund for Coal and Steel (RFCS) under the grant agreement number 753993.

\section{REFERENCES}

CEN, 2005. EN 1993-1-1: Eurocode 3 - Design of steel structures Part 1-1: General rules and rules for buildings. Brussels.

CEN. 2007. EN 1993-3-1: Eurocode 3 - Design of steel structures Part 3-1: towers, masts and chimneys Towers and masts. Brussels.

Kettler, M. \& Unterweger, H. 2017. Tragfähigkeit von Winkelprofilen bei Druckbeanspruchungen und realen Lagerungsbedingungen. Stahlbau 86(3): 239-255.

Kindmann, R., Laumann, J., Vette, J. 2013. Program FE-STAB. https://www.stahlbau.ruhr-uni-bochum. de/sb/service/rubsteeltools.html.de.

Rondal, J. \& Maquoi, R. 1979. Formulations d'Ayrton-Perry pour le Flambement des Barres Métalliques. Revue Construction Métallique 1979(4): 41-53.

Moze, P., Cajot, L.-G., Sinur, F., Rejec, K., Beg, D. 2014. Residual stress distribution of large steel equal leg angles. Engineering Structures 71: 35-47.

Spiliopoulos, A., Dasiou, M.-E., Thanopoulos, P., Vayas, I. 2017. Experimental tests on members made from rolled angle sections. Steel Construction 11(3): 1-10.

Vayas, I., Charalampakis, A., Koumousis, V., 2009, "Inelastic resistance of angle sections subjected to biaxial bending and normal forces“, Steel Construction 2(2): 138-146. 